\title{
Kink bands in thrust regime: Examples from Srinagar-Garhwal area, Uttarakhand, India
}

\author{
Shashank Shekhar*, A M Bhola and P S Saklani \\ Department of Geology, University of Delhi, Delhi 110 00\%, India. \\ Note: Prof. P.S. Saklani has retired from Department of Geology, University of Delhi \\ ${ }^{*}$ Corresponding author.e-mail: shashankshekhar01@gmail.com
}

This paper deciphers the late stress systems involved in the development of kink bands in the perspective of thrust regime. In kink bands, the correlation coefficient for $\alpha-\beta$ plots is positive near thrusts and negative away from thrusts. The plots show nearly linear relationship near thrusts and non-linear relationship away from thrusts. The rotation was prominent mechanism of kink band formation near thrusts and rotation coupled with shearing, along the kink planes away from thrusts. Along thrusts $\sigma_{1}$ is horizontal $\mathrm{E}-\mathrm{W}$ trend and it rotates to horizontal $\mathrm{N}-\mathrm{S}$ trend away from the thrust. The proposed model establishes that (1) the shearing along kink planes led to angular relationship, $\beta<\alpha$ and (2) the kink planes of conjugate kinks could be used for paleostress analysis even in those cases where shearing along these planes has occurred.

\section{Introduction}

The study area is located in Lesser Himalayas in Pauri-Garhwal, Uttarakhand, India. It lies between $30^{\circ} 12^{\prime} \mathrm{N}-30^{\circ} 15^{\prime} \mathrm{N}$ and $78^{\circ} 44^{\prime} \mathrm{E}-78^{\circ} 52.5^{\prime} \mathrm{E}$. In the perspective of regional thrust system in the Himalayas, to the north of the study area is Main Central Thrust (MCT) and to the south of the study area is Main Boundary Thrust (MBT). The study area is located nearer to the MCT and the thrust system in the study area could be considered as a part of the root zone of MCT system (figure 1a) (Shekhar 2007).

The rock types, Srinagar phyllite, Kilkaleshwar metavolcanics, Sumari quartzite (Chandpur Group), Marora limestone, Garhwal slate and Koteshwar quartzite along with Chamdhar metabasics, belong to the Garhwal Group (figure 1b). The Srinagar phyllite is thrust over Koteshwar quartzite, Garhwal slate and Marora limestone along North Almora Thrust (NAT). The phyllitic thrust sheet is exposed as major anticlines and synclines that are cut by Barkot and Koteshwar faults trending NESW and NNE-SSW, respectively. The main tectonic element of the area, i.e., NAT was designated by Valdiya $(1962,1968,1978)$ as Saryu thrust while Jain (1971) called it as Dharasu thrust. Saklani (1971, 1974, 1978, 1993 and 2006) described NAT as Dharkot thrust in adjoining areas. There is another smaller thrust in the southern part of the area designated as Sumari thrust in this paper.

The Chandpur and Garhwal Group rocks have undergone three phases of folding producing prominent foliation planes. Kink bands are extensively developed on the foliation planes of Srinagar phyllite of Chandpur Group. The NAT dip towards south and Sumari thrust dip towards north (figure 1b) as such the Srinagar phyllite occurs as hanging wall for both the thrusts. While the foot wall rocks in case of NAT belong to Garhwal Group and in case of Sumari thrust the footwall rocks consists of Sumari quartzite of Chandpur Group. The Barkot and Koteshwar faults are mostly restricted to Garhwal Group and do not extend much into

Keywords. Srinagar-Garhwal; kink bands; paleostress; shearing along kink planes; Himalaya; North Almora Thrust. 

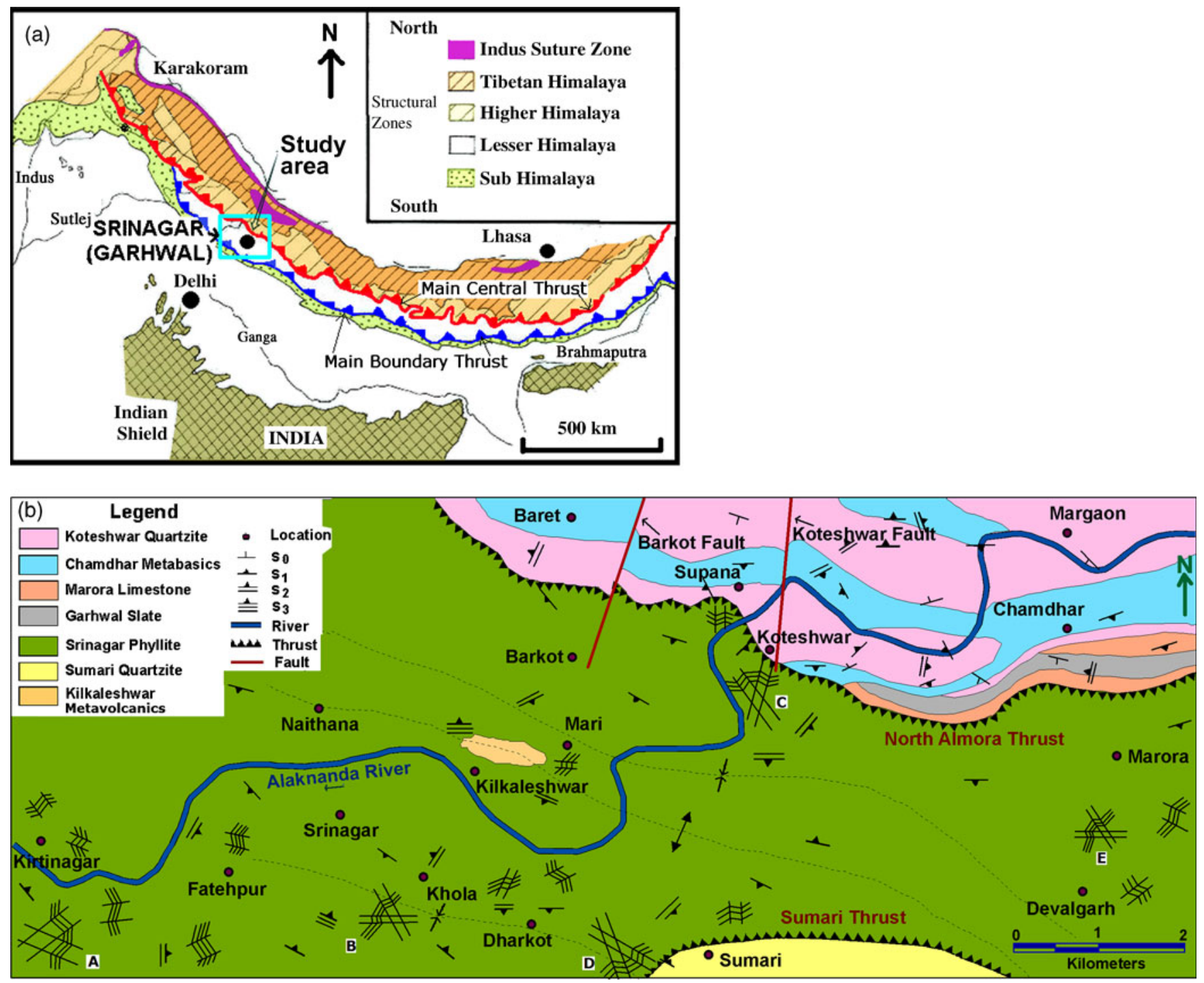

Figure 1. (a) General map of the Himalayas (after Gansser 1964) showing location of the study area. (b) Geology and structure of the Srinagar-Garhwal area with location of some of the outcrops showing kink bands. The numbers (a, b, etc.) have been put near to conjugate kink band locations for further reference in figure 9 .

the rocks of Chandpur Group. Since occurrence of kink bands are restricted to Srinagar phyllite of Chandpur Group, the major structures associated with kink bands in the study area are NAT and Sumari thrust (figure 1b). These kink bands belong to the third phase of deformation (Shekhar et al 2007). We have used these kink bands to decipher the variation in stress orientations with respect to the major thrusts in the area.

\section{Structure and tectonics}

The major structures are the NAT, the Sumari thrust, the Koteshwar fault, the Barkot fault, and vertical folds (preserved well in the Koteshwar quartzite of Garhwal Group), mainly observed near the intersection of river Alaknanda and Koteshwar fault on right bank of river Alaknanda (figure 1b), while the minor structures include $\mathrm{S}_{1}, \mathrm{~S}_{2}$ and $\mathrm{S}_{3}$ foliations, slicken sides, puckers and minor folds (figure 1b). In general, the NAT dips at moderate angles $\left(40^{\circ}\right.$ to $50^{\circ}$ towards SW) but at places it is steeper $\left(75^{\circ}\right.$ to $80^{\circ}$ towards SW) due to folding of the thrust plane (Shekhar et al 2006, 2007). The Sumari thrust in southern part of the area dips $50^{\circ}$ towards north. The Koteshwar and the Barkot faults are vertical-to-subvertical and are transverse in nature (figure $1 \mathrm{~b}$ ).

A schematic diagram showing down plunge section views of $\mathrm{F}_{1}, \mathrm{~F}_{2}, \mathrm{~F}_{3}$ folds, the interrelationship of $F_{1}, F_{2}$ and $F_{3}$ folds, and the related foliations is shown in figure 2 . The $F_{1}$ folds are recumbent and the $\mathrm{F}_{2}$ folds are asymmetric, and the $\mathrm{F}_{1}$ and $\mathrm{F}_{2}$ 

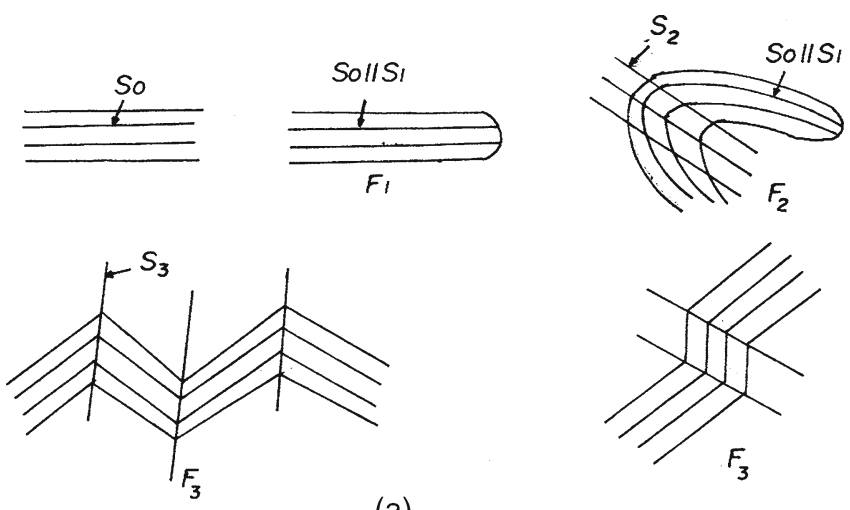

(a)

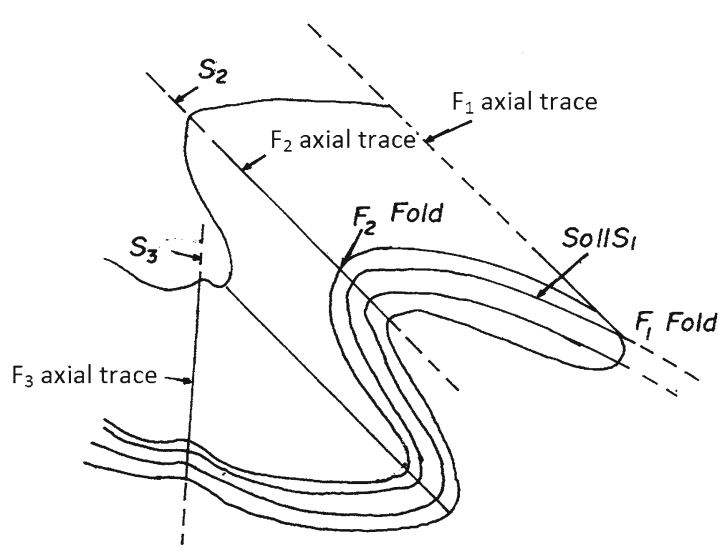

(b)

Figure 2. Schematic diagrams showing (a) down plunge section view of $\mathrm{F}_{1}, \mathrm{~F}_{2}$ and $\mathrm{F}_{3}$ folds and related foliations and (b) interrelationship of $\mathrm{F}_{1}, \mathrm{~F}_{2}$ and $\mathrm{F}_{3}$ folds and related foliations.

folds are co-axial, with axes plunging $70^{\circ}$ towards $251^{\circ}$ (figures $1 \mathrm{~b}, 3$ and $4 \mathrm{a}$ ). The $\mathrm{F}_{3}$ phase is represented by well-developed chevron folds and kink bands (figure 3 ). The $\mathrm{F}_{3}$ folds plunge $70^{\circ}$ towards $105^{\circ}$ (figure $1 \mathrm{~b}, 4 \mathrm{~b}$ ). The interference of $\mathrm{F}_{1}$ and $\mathrm{F}_{2}$ folds produced hook-shaped folds, whereas the interference of $F_{1} / F_{2}$ and $F_{3}$ folds produced type1 interference pattern (Ramsay 1967; Ramsay and Huber 1987; figures 3c and 2). The presence of chevron folds at certain places and kink bands at other places could be on account of strain variation.

The $S_{1}$ foliation is parallel to bedding $\left(S_{0}\right)$ and dips $\sim 60^{\circ}$ towards $\mathrm{S}$ and $\mathrm{SW}$, the dip direction shows variation and at places it also dips in the range of $60^{\circ}$ towards $\mathrm{N}$ and $\mathrm{NE}$. The $\mathrm{S}_{2}$ foliation resulted due to $F_{2}$ folding phase which dips at about $80^{\circ}$ towards east and west. The $\mathrm{S}_{3}$ foliation plane is produced by $\mathrm{F}_{3}$ event and dips $85^{\circ}$ towards north and south. The pi diagram of $\mathrm{S}_{1}, \mathrm{~S}_{2}$ and $\mathrm{S}_{3}$ foliations is shown in figure 4 . Since $S_{1}$ foliation is parallel to $S_{0}$ foliations, their pole plotting coincide on pi diagram and the inferred $\Pi$ axis represents both $\mathrm{F}_{1}$ and $\mathrm{F}_{2}$ axes. The mean vector of observed $\mathrm{F}_{1}$ and $\mathrm{F}_{2}$ fold axes and pucker axis lineations are shown in figure 4(a). The S-pole contour diagram of $S_{2}$ planes, the resultant $\Pi$ axis (inferred $F_{3}$ axis) and mean vector of observed $\mathrm{F}_{3}$ fold axes are shown in figure 4(b). The S-pole contour diagram of $\mathrm{S}_{3}$ planes is shown in figure 4(c).

The statistical analysis of foliation plane data and minor fold axes (figure 4) was done using software created by Allmendinger (2002). The statistical analysis of the mesoscopic fabric revealed that the trend of observed $\mathrm{F}_{1} / \mathrm{F}_{2}$ and $\mathrm{F}_{3}$ axes and statistically inferred $\mathrm{F}_{1} / \mathrm{F}_{2}$ and $\mathrm{F}_{3}$ axes from S-pole contour diagram shows angular difference of about $90^{\circ}$. Thus if we consider the observed fold axes, then the $\mathrm{F}_{1} / \mathrm{F}_{2}$ and $\mathrm{F}_{3}$ axes are found to be plunging opposite to each other in west and east directions respectively at a relatively steep angle. While the statistically inferred $\mathrm{F}_{1} / \mathrm{F}_{2}$ ( $\Pi$ axis in figure $4 \mathrm{a}$ ) and $\mathrm{F}_{3}$ axes ( $\Pi$ axis in figure $4 \mathrm{~b}$ ) are found plunging in the same direction (south) with $\mathrm{F}_{1} / \mathrm{F}_{2}$ axes plunging gently compared to $\mathrm{F}_{3}$ axis (figure 4). In light of the above anomaly, Shekhar et al (2007) opined that $\mathrm{F}_{1}, \mathrm{~F}_{2}$ and $\mathrm{F}_{3}$ axes and the related foliation planes were rotated by about $90^{\circ}$. They are of the view that the stress involved in producing the rotational movement was latter to the stress giving rise to $\mathrm{F}_{3}$ fold axes. This suggests that the rotational movement was a late stress phenomenon.

\section{The kink bands}

The geometry of kink bands with various parameters is shown in figure 5. The width of kink band $(\mathrm{W})$ is measured perpendicular to kink planes and length of kink band is measured parallel to kink planes. The length of rotated foliae is 1 . The angle between unkinked foliae and kink planes is $\alpha$, while $\beta$ is the angle between the kinked foliae and kink plane, and gamma $(\gamma)$ is the angle between external and internal foliae (figure 5).

The kink band analysis in the study area revealed that kink bands were product of the third and last phase of deformation. The kink bands were studied in vicinity of NAT as well as in areas away from it. They are both monoclonal and conjugate (figures $1 \mathrm{~b}, 3 \mathrm{a}, 3 \mathrm{~b}$ ). There is predominance of sinistral kink band in the area to the extent that nearly $79 \%$ of the recorded kink bands are sinistral, while $21 \%$ of the kink bands were dextral. The location of some of the outcrops showing kink bands in the area is shown in figure 1(b). The orthogonal thickness of kink bands is mostly in the range of 3-30 cm. The continuity of foliation across the kink bands in general is observed in the thin sections of kinked formations. However, at places, the truncation and thinning of quartz grains along kink planes are observed. Voids and dilatant zones along the kink planes have also been observed in 


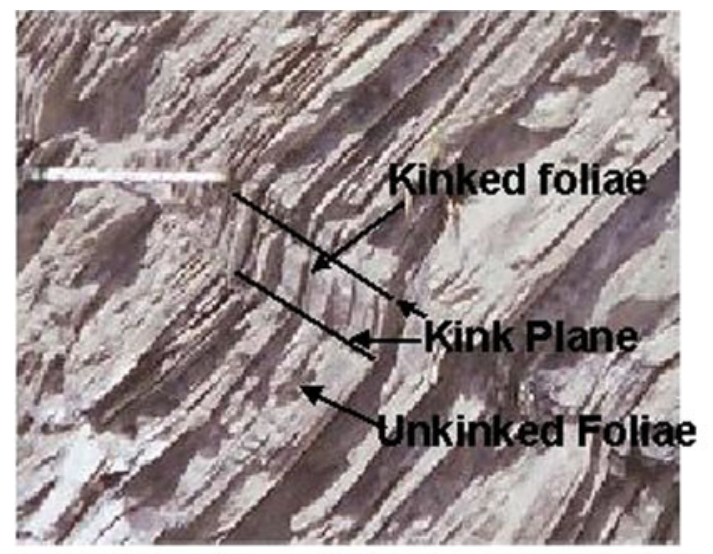

(a)

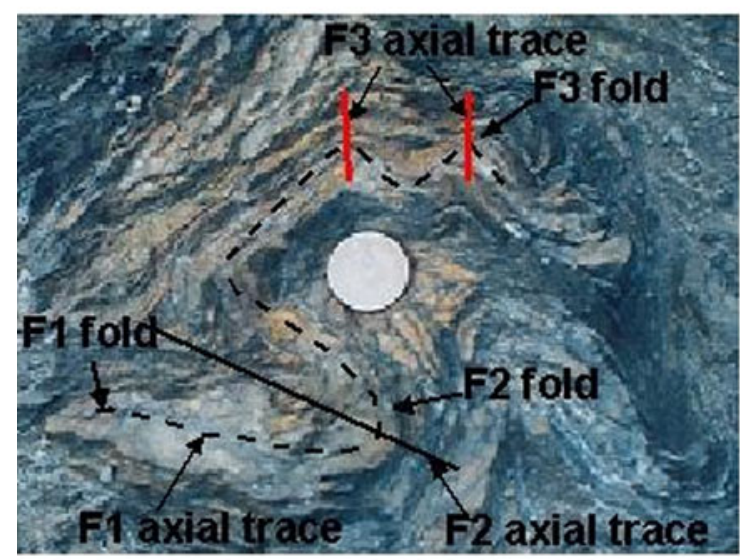

(c)

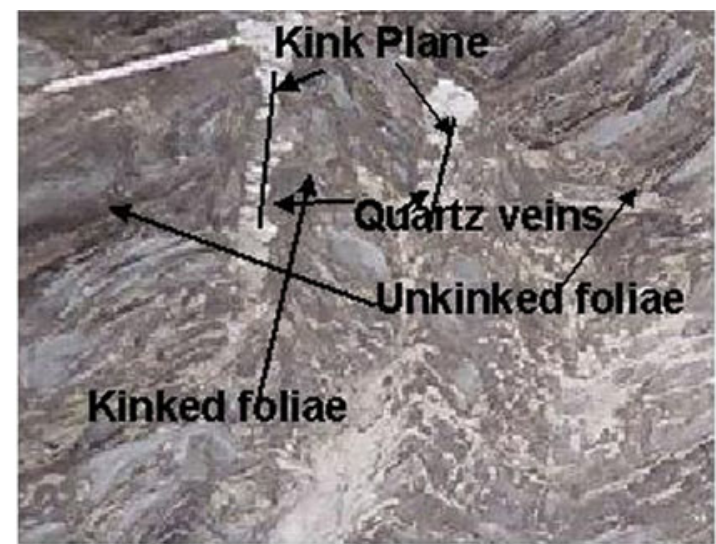

(b)

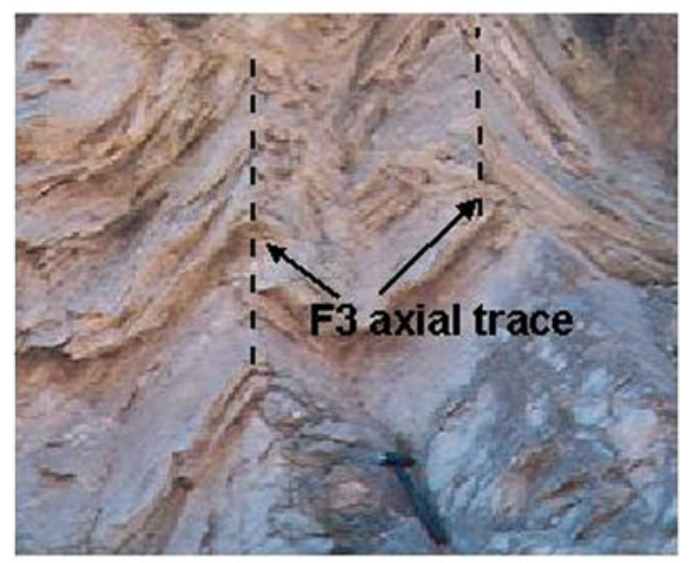

(d)

Figure 3. (a) Sinistral kink bands in plan view in Srinagar phyllite (location: Chamdhar to Devalgarh road around $3 \mathrm{~km}$ from Chamdhar). (b) Dextral kink bands in plan view in Srinagar phyllite with quartz veins along the kink planes (location: Kirtinagar). (c) Photograph showing subsequent refolding of minor fold axes in Srinagar phyllite (location: Koteshwar bridge). (d) Plunging chevron folds in Srinagar phyllite (location: Kirtinagar).

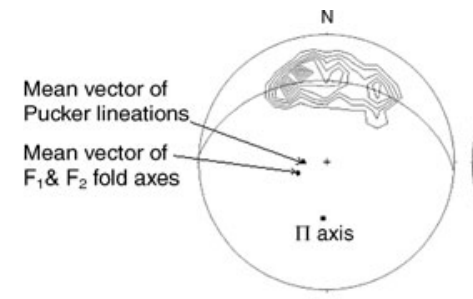

(a)

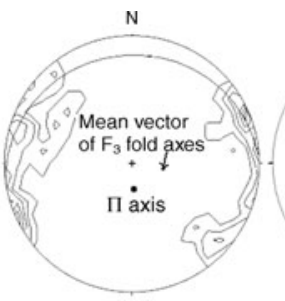

(b)

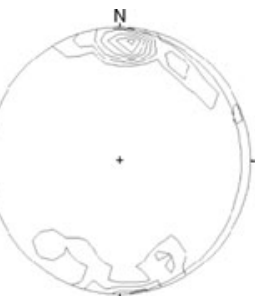

(c)

Figure 4. (a) S-pole contoured diagram (contour interval $=2 \%$ per $1 \%$ area, $\mathrm{N}=59$ ) of $\mathrm{S}_{0}$ and $\mathrm{S}_{1}$ surfaces in SrinagarGarhwal area with plot of $\Pi$ axis (inferred $F_{1}$ and $F_{2}$ axes, trend/plunge: $181^{\circ} / 54^{\circ}$ ), mean vector of $F_{1}(N=40)$ and $F_{2}$ $(\mathrm{N}=76)$ fold axes, trend/plunge: $251^{\circ} / 70^{\circ}$ and mean vector of pucker lineations $\left(\mathrm{F}_{2}\right)(\mathrm{N}=26)\left(\right.$ trend $/$ plunge: $\left.267^{\circ} / 74^{\circ}\right)$. (b) S-pole contoured diagram (contour interval $=2 \%$ per $1 \%$ area, $\mathrm{N}=91$ ) of $\mathrm{S}_{2}$ surfaces in Srinagar-Garhwal area with plot of $\Pi$ axis (inferred $\mathrm{F}_{3}$ axis, trend/plunge: $178^{\circ} / 74^{\circ}$ ) and mean vector of $\mathrm{F}_{3}$ fold axes $(\mathrm{N}=48)\left(\right.$ trend $/$ plunge: $\left.105^{\circ} / 70^{\circ}\right)$. (c) S-pole contoured diagram (contour interval $=2 \%$ per $1 \%$ area, $\mathrm{N}=127$ ) of $\mathrm{S}_{3}$ surfaces in Srinagar-Garhwal area.

outcrop and thin sections. Mostly the kink bands in thin sections show planar limbs, subangular to sharp hinges and continuity of lamellae across the kink planes. In some of the thin sections rounded to subangular hinges of the kink bands, textural modification and differential solution in the kink bands are noticed. These features of the kink bands help us in understanding the kinematics associated with kink band formation. It has been discussed in detail further in the text. 


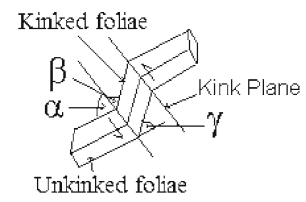

(a) Sinistral Kink band

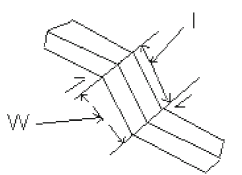

(b) Dextral Kink band

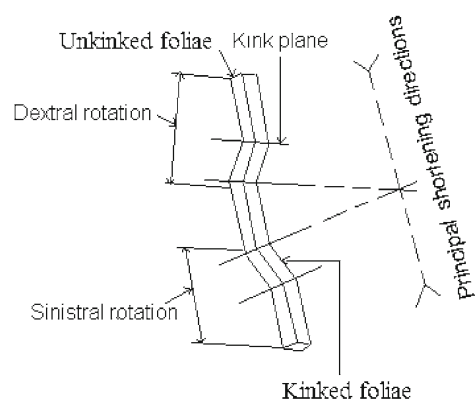

(c) Conjugate Kink band

Figure 5. The geometry of kink bands and different parameters in (a) sinistral, (b) dextral, and (c) conjugate kink bands.

\subsection{Angular relationship in kink bands}

The angles $\alpha, \gamma$ and $\beta$ were measured in kink bands of the study area. There is variation in $\alpha$ and $\beta$ angles. The value of $\beta$ exceeds $\alpha$ in $53 \%$ of the measured kink bands indicating towards general tendency of dilation within individual kink bands and volume increase inside individual kink bands due to fixed hinge kinking. The value of $\alpha$ exceeds $\beta$ in $44 \%$ of the measured kink bands indicating towards volume decrease inside individual kink bands. In $3 \%$ of the total measured kink bands $\alpha$ is equal to $\beta$ indicating no volume change within the kink bands. The angular relationships in kink bands were analyzed with relationship between the angles $\alpha$ and $\beta$. Besides analytical evaluation (in terms of kink band showing $\alpha>\beta$ geometry and vice versa) of the interrelationship between angles $\alpha$ and $\beta$, the scatter plots of angular parameters were analyzed. On the scatter plot of angles $\alpha$ and $\beta$, the correlation among these parameters were studied. The angular parameters when analyzed in aggregate for the whole study area, it did not show any consistent relationship between $\alpha$ and $\beta$ angles.

\subsection{Angular relationship in kink bands adjacent to the thrusts}

The areas near to the thrusts (Koteshwar, Sumari and Dharkot Khola areas, figure $1 \mathrm{~b}$ ) have $\beta$ angle greater than $\alpha$ angle in nearly $70 \%$ of the kink band measurements, whereas $30 \%$ of the measurements showed $\beta$ angle to be less than $\alpha$ angle. The angular relationship of kink bands in areas near to the thrusts, when analyzed using scatter plot and correlation coefficient approach showed good results (figure 6). The correlation coefficient for the plot between $\alpha$ and $\beta$ incorporating both sinistral and dextral kink band data together is positive and the plots showed nearly linear relationship between $\alpha$ and $\beta$.

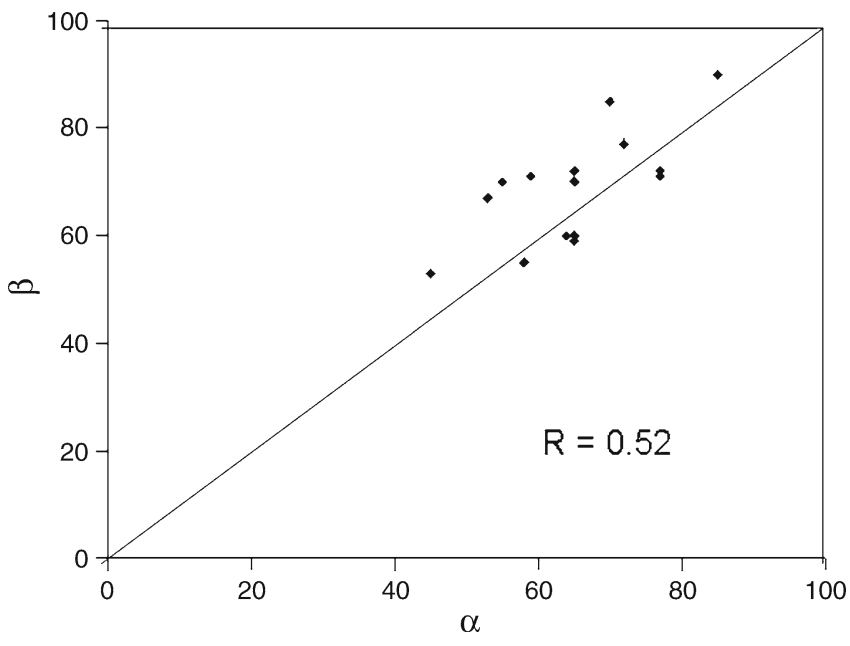

Figure 6. Plot of outer angle $\alpha$ (angle between unkinked foliae and kink plane) vs. inner angle $\beta$ (angle between kink plane and kinked foliae) in the region near the NAT and Sumari thrusts in Srinagar-Garhwal area.

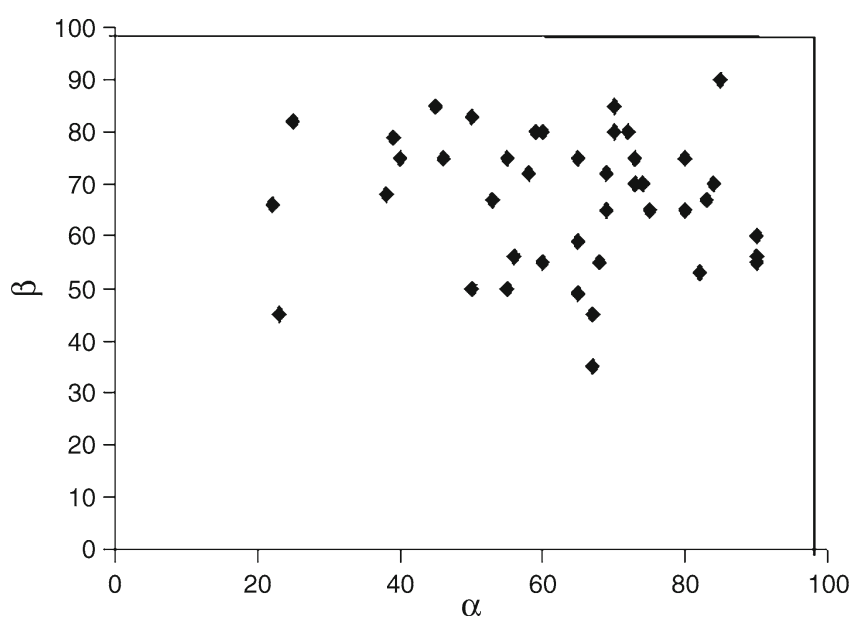

Figure 7. Plot of outer angle $\alpha$ (angle between unkinked foliae and kink plane) vs. inner angle $\beta$ (angle between kink plane and kinked foliae) in the region away from the NAT and Sumari thrusts in Srinagar-Garhwal area.

\subsection{Angular relationship in kink bands away from the thrusts}

In areas located away from the thrusts, e.g., Devalgarh, Khola, Mari, Naithana, Fatehpur and Kirtinagar area (figure 1b), about $60 \%$ of the kink bands show $\alpha$ to be greater than $\beta$ while $30-40 \%$ measurements show $\alpha$ to be less than $\beta$. In some isolated cases $\alpha$ is equal to $\beta$. In regions away from the thrusts, the scatter plot of $\alpha$ versus $\beta$ angles does not show any correlation between $\alpha$ and $\beta$ angles (figure 7). The kink bands in areas away from the thrust do not show any ideal geometry. The probable reason for such variation in $\alpha$ and $\beta$ of the individual kink bands and the variation in related geometry of the kink bands is the shearing 
along kink planes in the areas that are away from the thrusts. Thus the angular relationship and geometry of kink bands show a distinct variation in areas adjacent to the thrusts and away from it.

\subsection{The volumetric strain in the kinked folia}

It was calculated using the formulae:

$$
\begin{aligned}
& \text { Volumetric strain }=(\sin \alpha / \sin \beta)-1 \\
& \quad(\text { after Sharma and Bhola 2005) }
\end{aligned}
$$

The value of volumetric strain in the kinked folia ranges from -0.0012 to 0.6158 .

\section{Kinematics}

Kinematic models for the formation of kink band under different set-up has been proposed by Patterson and Weiss (1962, 1966); Donath (1968a); Cobbold et al (1971); Gay and Weiss (1974); Weiss (1980); Stubley (1990); Stewart and Alvarez (1991); Wadee et al (2004); Wadee and Edmunds (2005). The two distinct mechanisms for the formation of kink bands are:

- Nucleation of kink bands and their expansion by lateral migration.

- Rotation of limbs along fixed kink hinges, i.e., rotation of the foliation segment inside kink bands with respect to the outside foliation orientation.

The kink band formation mechanism model involving nucleation of kink bands and its expansion by lateral migration has been inferred in deformed phyllites (Patterson and Weiss 1966) and in experimentally deformed modelling materials (Weiss 1968; Honea and Johnson 1976) but the model is rarely validated in natural kink bands (Cobbold 1976; Stewart et al 1984; Beutner and Diegel 1985). In a material with a strong planar anisotropy, the theoretical model of folding by nucleation and growth was suggested by Weiss (1980) and Cobbold et al (1984). Wadee et al (2004) modelled mechanism for kink band initiation, broadening and subsequent restabilization. Wadee and Edmunds (2005) proposed kink band propagation mechanism.

Hunt et al (2000) opined that the formation of kink bands is a jump phenomenon, where previously stored energy is released from layer parallel stiffness. Many workers have attempted to apply some of the models to natural rocks in the field (Anderson 1968; Clifford 1968; Roberts 1971; Garnett 1974; Verbeek 1978; Roussel 1980; Bhola and Saberwal 1982).
The second mechanism emphasizes on fixed kink hinges to material plane and rotation of limbs about the fixed kink hinges along the kink planes, were favoured by Anderson (1964, 1968); Dewey (1965); Donath (1968a); Ramsay (1974) and Verbeek (1978). The theoretical studies of folding based on buckle (Biot 1964, 1965; Johnson and Ellen 1974; Latham 1985a, 1985b) also favoured fixed hinge folding. Sharma and Bhola (2005) proposed rotation-dilation mechanism for the development of kink bands from Chamba region of western Himalayas.

Jiang et al (2004) on the basis of numerical modelling proposed that there are two competing mechanisms of deformation, one is strain localization which leads to development of kink bands and the other is deformation of kink bands. They are of the view that kink band migration and rotation is limited and is not the primary mechanism for development of kink folds.

The morphology of kink bands, angular relationship in the kink bands and microstructural characteristics of kinks were studied to suggest a probable mechanism of kink band formation. Morphologically some of the distinct features observed in the kinked formations are like dilatant zone along the kink plane filled with quartz veins and parted lamellae. The kink bands mostly have planar limbs, subangular to sharp hinges and continuity of lamellae across the kink planes. In general, the continuity of foliation across kink bands has been observed. While some of the kink bands show pressure solution effects on quartz grains along kink planes. In some micro-kinks, voids and dilatant zones along the kink planes were present. With regards to angular relationship $\beta>\alpha$ geometry has been observed in majority of kink bands adjacent to the thrusts. These features suggest that rotation was a prominent mechanism in kink band formation.

In contrast to this some of the kink bands show rounded-to-subangular hinges and a few show angular relationship where $\alpha=\beta$. Some micro kink bands also reveal rounded-to-subangular hinges of the kink bands, textural modification and differential solution. These features point that during rotation mechanism where kinks were not jammed, some kink bands probably attained the geometry as suggested for the formation of kink bands in the migration model and simple shear zone model. In areas away from thrusts majority of the kink bands show $\alpha>\beta$ geometry. The $\alpha>\beta$ geometry observed in kink bands suggest towards shearing as a common phenomenon along the kink planes (Anderson 1964). Since considerable study area is away from thrusts showing $\alpha>\beta$ geometry in majority of kink bands, it becomes important to assess the role of shearing along kink planes in kink bands. 
The effect of shearing along kink planes on the angular parameters of kink bands and the related strains was studied with help of a simple schematic model (figure 8). The model assumes value of angle $\alpha$ (the angle between unkinked foliae and kink plane) as constant and the value of angle $\Phi$ (angle between a line perpendicular to the foliation and the kink plane) as constant with an objective to make the model simple and easily understandable. The new angular parameter $\Phi$ was considered to facilitate quantification of transverse strain using formulae:

$$
\text { Transverse strain }=1-\cos (\Phi)
$$

(Wadee and Edmunds 2005) .

The angular shear for the kinked folia was calculated along an imaginary line perpendicular to

(a) Unkinked formation

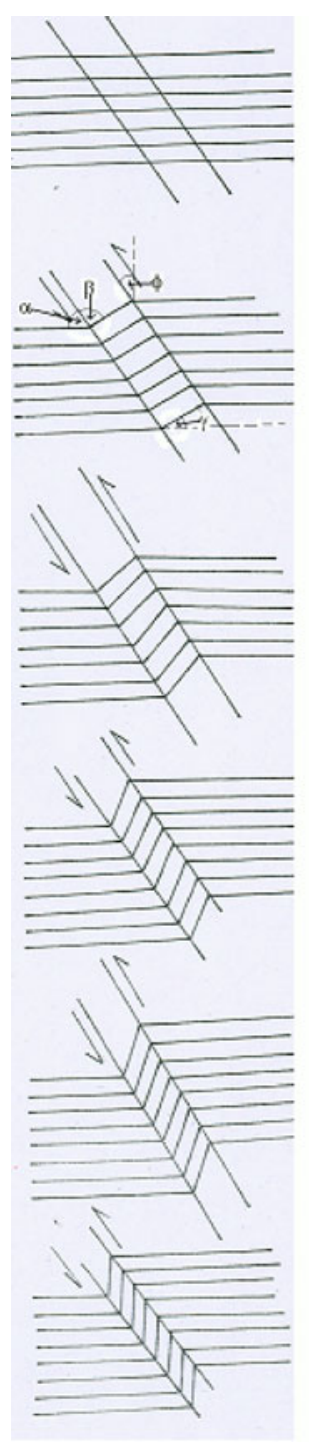

(b)

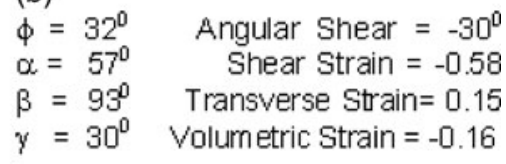

(c)

$\phi=32^{0} \quad$ Angular Shear $=-43^{\circ}$

$\alpha=57^{0} \quad$ Shear Strain $=-0.93$

$\beta=80^{\circ} \quad$ Transverse Strain $=0.15$

$y=43^{0} \quad$ volumetric Strain $=-0.15$

(d) $\begin{array}{lr}\phi=32^{\circ} & \text { Angular Shear }=-67^{0} \\ \alpha=57^{\circ} & \text { Shear Strain }=-2.36 \\ \beta=56^{\circ} & \text { Transverse Strain }=0.15 \\ y=67^{\circ} & \text { Volumetric Strain }=0.01\end{array}$

(e)

$\phi=32^{0}$

$\alpha=57^{0}$

$\beta=48^{\circ}$

$y=75^{0}$

(f)

$\phi=32^{0} \quad$ Angular Shear $=-82^{0}$

$\alpha=57^{0} \quad$ Shear Strain $=-7.12$

$\beta=41^{\circ} \quad$ Transverse Strain $=0.15$

$y=82^{0} \quad$ volumetric Strain $=0.28$

Figure 8. Schematic model showing shearing along kink planes and its effect on the angular parameters and the related strain in a kinked formation. the unkinked folia. In a sinistral kink band model shown in figure 8 , the angular rotation is anticlockwise and is denoted by a negative sign preceding the value of angular shear. The angle $\gamma$ (angle through which kinked foliae are rotated) is a measure of angular shear along a line perpendicular to the unkinked folia. The shear strain in the kinked folia was calculated using the formulae:

$$
\begin{aligned}
& \text { Shear strain }=\tan (\text { angular shear }) \\
& \quad(\text { taken from Davis and Reynolds 1996) } \\
& \text { Shear strain }=\tan (\gamma)
\end{aligned}
$$

Depending on the nature of rotation, the angular shear has positive or negative sign (positive sign for clockwise rotation of dextral kink bands and negative sign for anticlockwise rotation of sinistral kink bands (Davis and Reynolds 1996)). The positive and negative signs of shear strain have only directional connotation, indicating direction of rotation in the kinked folia.

The volumetric strain in the kinked folia was calculated using the formulae (Sharma and Bhola 2005) given earlier as equation (1). The negative and positive signs preceding the volumetric strain have relationship with the magnitude, and as such volumetric strain of -0.16 is less than the volumetric strain of -0.15 . In the schematic model given in figure 8, the value of angle $\alpha$ was assumed to be constant. Thus the change in volumetric strain is due to change in angle $\beta$. Since $\sin \beta$ is in denominator of the equation (1), as the value of $\beta$ decreases, the value of volumetric strain increases in the model. Keeping the assumption of model (that is $\Phi$ and $\alpha$ angles are constant) in mind, it can be said that shearing along kink planes progressed with the magnitude of volumetric strain.

The model (figure 8) also shows that in normal kink bands ( $\beta>\alpha$ geometry), when shearing along kink planes occur, the value of $\beta$ angle decreases gradually and reaches a stage where $\beta<\alpha$. However, as shown in the model this phenomenon of shearing along the kink planes only affected the angular parameters of the kink band and not the attitude of kink planes, which was same before and after shearing along the kink planes.

A combination of different mechanism proposed in the kinematic models of kink band formation possibly operated to form kink bands in the study area. The most prominent mechanism seems to be rotation coupled with shearing along the kink planes, which was active during the formation of a majority of the kink bands. In fact, rotation was the most prominent mechanism in kink band formation in areas near the thrust. In areas away from the thrust the rotation coupled with shearing along the kink planes was a prominent mechanism. 


\section{Dynamics}

The kink bands observed are singular sinistral, dextral and conjugate. The kink bands were used as palaeostress indicators during the late stress system and their dynamic significance was already discussed by Patterson and Weiss (1966); Donath (1968b); Anderson (1974); Gay and Weiss (1974). The maximum compressive stress $\sigma_{1}$ wherever lies or is very near to $S_{1}$, the conjugate kink sets were formed. When $\sigma_{1}$ is greater than $25^{\circ}$ with $\mathrm{S}_{1}$, the conjugate kink bands were replaced by a simple set of kink bands (Patterson and Weiss 1966). The conjugate kink bands are commonly used to determine late stress orientation in orogenic belts (Ramsay 1962; Anderson 1969; Gay and Weiss 1974; Verbeek 1978; Weiss 1980). It involves determination of angular bisectrix between the conjugate pairs of kink planes (Ramsay and Huber 1987). The bisectrix of obtuse angle between conjugate pair of kink bands is taken as direction of maximum compressive stress $\left(\sigma_{1}\right)$, while $\sigma_{2}$, the intermediate stress direction is taken as the line of intersection of conjugate kink bands. The minimum compressive stress $\sigma_{3}$ is normal to $\sigma_{1}-\sigma_{2}$ plane bisecting acute angle between conjugate kinks. It has been observed that inclination of kink planes to $\sigma_{1}$ varies between $67^{\circ}$ and $60^{\circ}$ (Patterson and Weiss 1966; Donath 1968a). Srivastava et al (1998, 1999) suggested an alternative approach where triangular plot method was used for palaeostress analysis of orthorhombic kink bands together with a fault slip method for palaeostress analysis. The effort in palaeostress analysis was also extended to single sets of kink bands (Clifford 1968). Debacker et al (2008) cautioned using kink bands to deduce regional palaeostress patterns and suggested that one should not extrapolate the inferred palaeostress outside the region under study.

The conjugate kink bands of the area are asymmetric contractional kink bands. Near the Sumari thrust, it has been established that the contractional kink bands show $\alpha \leq \beta<90^{\circ}$. This angular relationship $\left(\alpha \leq \beta<90^{\circ}\right)$ is observed in totality in the sinistral pair of Koteshwar conjugate kinks near to NAT. In areas away from thrust, angle $\beta<$ $90^{\circ}$ and it is also less than angle $\alpha$ indicating shearing along kink planes. The kink bands analyzed along or near to the thrusts show angular geometry and angular parameters like $\beta>\alpha$ pointing that the kink bands experienced volume increase. As mentioned earlier, the kink band geometry in areas away from the thrusts was influenced by shearing along kink planes. Thus it was necessary to assess whether shearing along kink plane affected the attitude of principal stress direction (i.e., $\sigma_{1}, \sigma_{2}$ and $\left.\sigma_{3}\right)$. It was established in kink band model (figure 8) that shearing along kink planes did not affect attitude of kink planes. Since the attitude of principal stress directions depended on the attitude of kink planes, it can be said that the phenomenon of shearing along the kink planes did not apparently affect the principal stress directions. Hence kink planes of conjugate kink bands in areas away from the thrust could be used for palaeostress analysis, even in cases where some kink bands might have experienced shearing along kink planes. The palaeostress analysis of conjugate kinks reveal that the stress pattern along the thrust was such that $\sigma_{3}$ acquired near verticality and $\sigma_{1}$ near horizontality (trending approximately $\mathrm{E}-\mathrm{W}$ ) along the trace of thrusts in plan (figure 9). Even in areas away from thrusts $\sigma_{3}$ acquired near verticality and $\sigma_{1}$ near horizontality (trending approximately N-S) (figure 9). Therefore away from the thrust, the tendency of verticality of $\sigma_{3}$ and horizontality of $\sigma_{1}$ was maintained but the direction of $\sigma_{1}$ was different in areas near to the thrust and away from it (figure 9). The verticality of $\sigma_{3}$ and horizontality of $\sigma_{1}$ is similar to the stress system required for the formation of thrusts or reverse faults, hence it is suggested that development of kink band were related to phenomenon of thrusting and the kink bands were developed during the process of thrusting. Srivastava and Sahay (2003) while working on

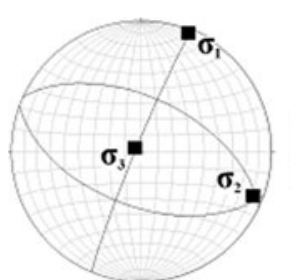

(a)

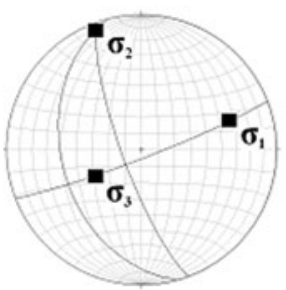

(d)

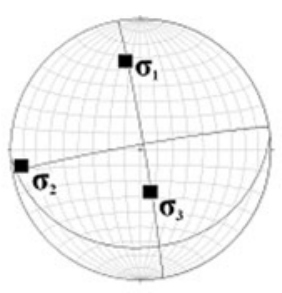

(b)

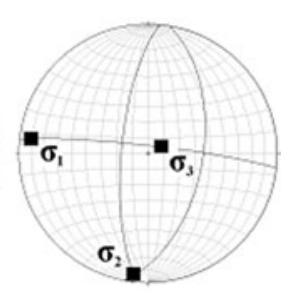

(c)

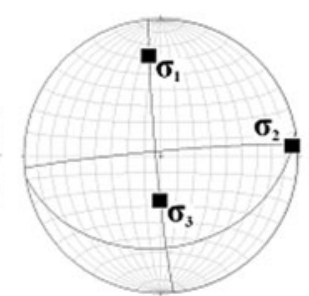

(e)

Figure 9. Plot of paleostress directions as stereograms, corresponding to conjugate kink bands in Srinagar-Garhwal area. The number underneath individual stereograms corresponds to locations of conjugate kink bands as indicated on figure $1(\mathbf{b})$. The stereograms shown as (c) (trend/ plunge: $\sigma_{1}-277^{\circ} / 9^{\circ}, \quad \sigma_{2}-187^{\circ} / 5^{\circ}$ and $\left.\sigma_{3}-68^{\circ} / 80^{\circ}\right)$ and (d) (trend/plunge: $\sigma_{1}-72^{\circ} / 31^{\circ}, \sigma_{2}-339^{\circ} / 5^{\circ}$ and $\sigma_{3}-241^{\circ} / 62^{\circ}$ ) correspond to conjugate kink band near North Almora Thrust and Sumari Thrust respectively, while other stereograms (a) (trend/plunge: $\sigma_{1}-23^{\circ} / 0^{\circ}$, $\sigma_{2}-113^{\circ} / 4^{\circ}$ and $\sigma_{3}-285^{\circ} / 86^{\circ}$ ), (b) (trend/plunge: $\sigma_{1}-$ $352^{\circ} / 31^{\circ}, \sigma_{2}-260^{\circ} / 2^{\circ}$ and $\sigma_{3}-166^{\circ} / 65^{\circ}$ ) and (e) (trend/ plunge: $\sigma_{1}-353^{\circ} / 27^{\circ}, \sigma_{2}-85^{\circ} / 3^{\circ}$ and $\left.\sigma_{3}-181^{\circ} / 65^{\circ}\right)$ represent conjugate kink bands away from the thrusts. 
kink bands in Chittaurgarh area of northwestern India had similar observations. The variation in principal stress direction $\sigma_{1}$ in regions near to the thrust and those away from the thrust was helpful to distinguish the conjugate kink bands near the thrust from those, which are away from it.

\section{Conclusions}

The kink bands near thrusts in Srinagar Garhwal area were formed by rotational mechanism. They show an ideal geometry, where the angular parameters $(\alpha$ and $\beta)$ of the kink bands correlate ideally with each other. In contrast in regions away from thrusts the kink bands were formed by rotation coupled with shearing along the kink plane. There the $\alpha$ and $\beta$ angles do not show any correlation and the kink band geometry is not ideal.

The palaeostress analysis suggested that kink bands developed during process of thrusting. The variation in $\sigma_{1}$ direction inferred from palaeostress analysis of kink bands is in conjunction to the earlier-mentioned findings of the statistical analysis of mesoscopic fabric (Shekhar et al 2007) and where it was established that the fold axes and related foliation planes were rotated by about $90^{\circ}$ during late stress period and the vertical folds were produced by rotation of the recumbent folds of earlier generation by about $90^{\circ}$. Thus the work successfully related stress and strain aspects in the late stress systems based on kink band development in relationship to the thrust tectonics. It brought out conclusive evidence of their relationship and the thrust tectonics, which may be a model for other Himalayan segments affected by thrusting.

\section{Acknowledgements}

The authors are grateful to Prof. Deepak C Srivastava, Indian Institute of Technology, Roorkee for the meticulous review which helped in improving the manuscript. The authors are also grateful to the anonymous reviewers for their constructive comments which helped in improving the manuscript.

\section{References}

Allmendinger R W 2002 Stereo Win for windows ftp://www.geo.cornell.edu/pub/rwa.

Anderson T B 1964 Kink-bands and related geological structures; Nature 202 272-274.

Anderson T B 1968 The geometry of natural orthorhombic system of kink-bands; In: Researches in Tectonics (eds) Baer A B and Norris D K, Geological Survey of Canada Paper 52-68, 200-219.
Anderson T B 1969 The geometry of a natural orthorhombic system of kink-bands; In: Kink bands and brittle deformation (eds) Baer A J and Norris D K, Geological Survey of Canada Paper 52-68, 200-220.

Anderson T B 1974 The relationship between kink-bands and shear fractures in the experimental deformation of slate; J. Geol. London 130 367-382.

Beutner E C and Diegel F A 1985 Determination of fold kinematics from syntectonic fibres in pressure shadows, Matinsburg slate, New Jersey; Am. J. Sci. 285 16-50.

Bhola A M and Saberwal K K 1982 Deformation structures in the Delhi Group of rocks around Nibhor, Rajasthan; J. Geol. Soc. 23(11) 521-538.

Biot M A 1964 Theory of internal buckling of a confined multilayered structure; Bull. Geol. Soc. Am. 75 563-568.

Biot M A 1965 Further development of the theory of internal buckling of multilayers; Bull. Geol. Soc. Am. 76 833-840.

Clifford P M 1968 Kink band development in the Lake St. Joseph area, northwestern Ontario; In: Proceeding of conference on research in tectonics (kink bands and brittle deformation) (eds) Baer A J and Norris D K, Geological Survey of Canada Paper 52-68, 229-241.

Cobbold P R 1976 Mechanical effects of anisotropy during large finite deformations; Bull. Soc. Geol. France $\mathbf{7}$ 1497-1510.

Cobbold P R, Cosgroove J W and Summer J M 1971 Development of internal structures in deformed anisotropic rocks; Tectonophys. 12 23-53.

Cobbold P R, Means W D and Bayley M B 1984 Jump in deformation gradients and particle velocity across propagating coherent boundaries; Tectonophys. 108 283-298.

Davis G H and Reynolds S J 1996 Structural Geology of Rocks and Regions; 2nd edn, John Wiley and Sons, Inc., $760 \mathrm{p}$.

Debacker T N, Seghedi A, Belmans M and Sintubin M 2008 Contractional kink bands formed by stress deflection along preexisting anisotropies? Examples from the Anglo-Brabant Deformation Belt (Belgium) and the North Dobrogea Orogen (Romania); J. Struct. Geol. 30 1047-1059.

Dewey J F 1965 Nature and origin of kink bands; Tectonophys. 1 459-494.

Donath F A 1968a The development of kink bands in brittle anisotropic rock; In: Igneous and metamorphic geology (eds) Prinz M and Manson V, Geol. Soc. Am. Bull. 115 453-493.

Donath F A 1968b Experimental study of kink-bands in Martinsberg slate; In: Researches in Tectonics (eds) Baer A J and Norris D K, Geological Survey of Canada Paper 52-68, 255-288.

Garnett J A 1974 A mechanism for the development of enechelon gashes in kink zones; Tectonophys. 21 287-300.

Gansser A 1964 Geology of Himalayas, Interscience Publishers, London, 289p.

Gay N C and Weiss L E 1974 The relationship between principal stress direction and geometry of kinks in foliated rocks; Tectonophys. 65 1-38.

Honea E and Johnson A M 1976 A theory of concentric kink and sinusoidal folding and of flexuring of compressible, elastic multilayers, part IV. Development of sinusoidal and kink folds in multilayers confined by rigid boundaries; Tectonophys. 30 197-239.

Hunt G W, Peletier M A and Wadee M A 2000 The Maxwell stability criterion in pseudo energy models of kink banding; J. Struct. Geol. 22 667-679.

Jain A K 1971 Stratigraphy and tectonics of the Lesser Himalayan region of Uttarkashi, Garhwal Himalaya; Him. Geol. 1 25-58. 
Jiang D, Williams P and Carter B 2004 Numerical modeling of the development of kink bands in anisotropic plastic materials; In: Numerical modeling of Microstructures (eds) Kohn D and Malthe-Sorensen A, Journal of the Virtual Explorer, Electronic Edition, ISSN 1441-8142, Volume 15, Paper-4.

Johnson A M and Ellen S D 1974 A theory of concentric, kink and sinusoidal folding and of monoclinal flexuring of compressible, elastic multilayers; Tectonophys. 21 301-339.

Latham J P 1985a A numerical investigation and geological discussion of the relationship between folding, kinking and faulting; J. Struct. Geol. 7 237-249.

Latham J P 1985b A numerical investigation and geological discussion of the relationship between folding, kinking and faulting; J. Struct. Geol. 7 237-249.

Patterson M S and Weiss L E 1962 Experimental folding in rocks; Nature 195 1046-1048.

Patterson M S and Weiss L E 1966 Experimental deformation and folding in phyllite; Bull. Geol. Soc. Am. 77 343-374.

Ramsay J G 1962 The geometry of conjugate kink systems; Geological Magazine 99 516-526.

Ramsay J G 1967 Folding and Fracturing of Rocks (McGraw-Hill: New York), 568p.

Ramsay J G 1974 Development of chevron folds; Bull. Geol. Soc. Am. 79 795-812.

Ramsay J G and Huber M I 1987 The Techiniques of Modern Structural Geology, V.2: Folds and Fractures (London: Academic Press), 381p.

Roberts D 1971 Stress regime and distortion of a conjugate fold system from the Trondheim region, Central Norway; Tectonophys. 12 155-165.

Roussel D H 1980 Kink bands in the Onaping Formations, Sudbury Basin, Ontario; Tectonophys. 66 83-97.

Saklani P S 1971 Structure and tectonics of the Pratapnagar area, Garhwal Himalaya; Him. Geol. 1 75-91.

Saklani P S 1974 Deformation of Quartz and Mica in Tectonics of Tehri Garhwal Himalaya; Publ. Centre Adv. Stud. Geol. Punjab Univ., Chandigarh 10 38-44.

Saklani P S 1978 Deformation and Tectonism of Mukhem Area, Lesser Himalaya; In: Tectonic Geology of the Himalaya (ed.) Saklani P S (New Dehi: Today and Tomorrows Publishers), pp. 15-42.

Saklani P S 1993 Geology of the Lower Himalaya (Garhwal); (New Delhi: International Books and Periodicals Supply Service), 246p.

Saklani P S 2006 Geology of the Garhwal Himalaya: Retrospect and Prospect; In: Himalaya (Geological Aspects) (ed.) Saklani P S (New Delhi: Satish Serial Publishing House) 4 129-152.

Sharma B K and Bhola A M 2005 Kink bands in the Chamba region, Western Himalaya, India; J. Asian Earth Sci. 25 $513-528$.

Shekhar S 2007 Geology and structure with special emphasis on kink band development around Srinagar-
Garhwal area, Uttarakhand, India, Unpublished PhD dissertation, Department of Geology, University of Delhi, Delhi.

Shekhar S, Saklani P S and Bhola A M 2006 Geology and structure of Srinagar, Garhwal-Himalaya; In: Himalaya (Geological Aspects) (ed.) Saklani P S (New Delhi: Satish Serial Publishing House) 4 153-169.

Shekhar S, Saklani P S and Bhola A M 2007 Vertical folds and Mesoscopic Fabrics in Srinagar area, Garhwal Himalaya; In: Himalaya (Geological Aspects) (ed.) Saklani P S (New Delhi: Satish Serial Publishing House) 5 199-210.

Srivastava D C and Sahay A 2003 Brittle tectonics and pore fluid conditions in the evolution of the Great Boundary Fault around Chittaurgarh, North Western India; J. Struct. Geol. 25 1713-1733.

Srivastava D C, Lisle R J, Imran M and Kandpal R 1998 The kink-band triangle: A triangular plot for paleostress analysis from kink bands; J. Struct. Geol. 20 1579-1585.

Srivastava D C, Lisle R J, Imran M and Kandpal R 1999 A new approach for paleostress analysis from kink bands: Application of fault slip methods; J. Geol. 107 $165-176$.

Stewart K G and Alvarez W 1991 Mobile-hinge kinking in layered rocks and models; J. Struct. Geol. 13 248-259.

Stewart K G, Alvarez W and Weiss L E 1984 A comparison between kink folds in pelagic limestones and modeling materials: Evidence for migrating kink band boundaries; Geol. Soc. Am. Abs. W. Prog. 16669.

Stubley M P 1990 The geometry and kinematics of a suite of conjugate kink bands, southeastern Australia; J. Struct. Geol. 12(8) 1019-1031.

Valdiya K S 1962 An outline of the stratigraphy and structure of the southern part of the Pithoragarh district U.P.; J. Geol. Soc. India 3 27-48.

Valdiya K S 1968 Origin of the Magnesite deposits of southern Pithoragarh, Kumaun Himalaya; Economic Geol. 63 924-934.

Valdiya K S 1978 Outline of the Structure of Kumaun Himalaya; In: Tectonic Geology of the Himalaya (ed.) Saklani P S (New Delhi: Today and Tommorrows Publishers) 1-14.

Verbeek E R 1978 Kink bands in Somport slates, West Central Pyreenes; France and Spain; Bull. Geol. Soc. Am. 89 814-24.

Wadee M A and Edmunds R 2005 Kink band propagation in layered structures; J. Mech. Phys. Solids 53 2017-2035.

Wadee M A, Hunt G W and Peletier M A 2004 Kink band instability in layered structures; J. Mech. Phys. Solids $\mathbf{5 2}$ 1071-1091.

Weiss L E 1968 Flexural slip folding of foliated model materials; In: Proc. Conference on Research in Tectonics (Kink bands and brittle deformation) (eds) Baer A J and Norris D K, pp. 294-333.

Weiss L E 1980 Nucleation and growth of kink bands; Tectonophys. 65 1-38. 